\title{
Mass-balance model parameter transferability on a tropical glacier
}

\author{
Wolfgang GURGISER, ${ }^{1}$ Thomas MÖLG, ${ }^{2}$ Lindsey NICHOLSON, ${ }^{1}$ Georg KASER ${ }^{1}$ \\ ${ }^{1}$ Center for Climate and Cryosphere, Institute for Meteorology and Geophysics, University of Innsbruck, Innsbruck, Austria \\ E-mail:wolfgang.gurgiser@uibk.ac.at \\ ${ }^{2}$ Chair of Climatology, Institute for Ecology, Technical University Berlin, Berlin, Germany
}

\begin{abstract}
We explore the small-scale spatial and temporal transferability of model parameters between two points in the ablation zone of tropical Glaciar Shallap, Cordillera Blanca, Peru $\left(9^{\circ} \mathrm{S}\right.$, $-77^{\circ} \mathrm{W} ; \sim \mathbf{4 8 0 0} \mathrm{m}$ a.s.l.) in order to provide a robust assessment of the performance of a process-based glacier mass-balance model. Relative surface height change is calculated at hourly time-steps, and cumulative values are compared to surface height measurements made at irregular intervals (14-64 days) over the course of two continuous hydrological years (August 2006-August 2008). Bestperforming parameter combinations were determined for each point from the outcome of 1000 model simulations for which parameters were varied randomly within a defined range. With these parameter combinations measurements for a specific location and time-span are well reproduced. Transferring the parameter combination as optimized for one location to the other location in the ablation zone increases the errors of modeled cumulative mass balance by $5-1326 \mathrm{~mm}$ ice eq. $\mathrm{a}^{-1}$. Transferring the parameter combinations as optimized for one year to the other year increases the modeled errors in cumulative mass balance by $18-3179 \mathrm{~mm}$ ice eq. $\mathrm{a}^{-1}$. Model errors generally increase during periods with frequent snowfall and snow cover. This could reflect either the inherent difficulty of modeling complex snow processes, or the inability of the model to correctly capture the pattern of albedo evolution at this site. The magnitude of errors associated with parameter transfer in space and time highlights the need for improving model performance for robust climatological and/or hydrological analyses on tropical glaciers.
\end{abstract}

\section{INTRODUCTION}

Mountain glaciers are important reservoirs in the regional hydrology of semi-arid regions such as the Peruvian Andes where glacier melt contributes significantly to available water during the pronounced dry seasons (e.g. Kaser and others, 2003; Mark and others, 2010; Viviroli and others, 2011). Projected glacier shrinkage in this region (Vuille and others, 2008; Rabatel and others, 2012) will impact the role of glaciers in regional hydrology: studies using simple, lowtemporal-resolution, glacier mass-balance models show that, in response to future climate scenarios, a smaller glacierized area will lead to reduced meltwater contribution to runoff in the dry season and increased direct runoff from rainfall in the wet season (Juen and others, 2007).

To understand the impact of atmospheric conditions on glacier mass balance and meltwater production, and to model hydrological resource fluctuations at high temporal resolution, process-based spatially distributed glacier massbalance models are required (Hock, 2005). These models typically need sub-daily meteorological input and parameterization of several variables (e.g. albedo, coefficients for turbulent fluxes or vertical gradients in meteorological conditions such as temperature and precipitation). In the harsh environment of the glaciated Peruvian Andes, data for constraining these parameters are usually only available for short periods at a small number of locations. Therefore, inputs for spatially distributed glacier mass-balance modeling rely on extrapolations of model parameters in space and time. In order to assess the validity of multi-annual glacierwide runoff assessments derived from such mass-balance models it is critical to understand and account for the impact of spatial and temporal transfer of model parameters on model results.
While the transferability of enhanced temperature-index models has been shown to be relatively robust (e.g. Carenzo and others, 2009), studies with process-based mass-balance models have demonstrated that spatial or temporal extrapolation of parameters optimized or measured at one point in space or time introduces error and affects the performance of the model at other locations and times on the glacier (e.g. Hock and Holmgren, 2005; Machguth and others, 2008; Reijmer and Hock, 2008; Sicart and others, 2011). In these studies, some parameterized components of the model were optimized at a single location; for example, coefficients used in parameterizing albedo were optimized on the basis of measurements at a single weather station, while other parameterized values (e.g. surface roughness) were adjusted to yield optimal agreement between model output and measurements of glacier-wide ablation and discharge where available. In cases like this, resultant deviations between modeled and measured ablation at individual stakes do not give direct information on transferability across the glacier surface as the model was optimized at a glacier-wide scale. To the best of our knowledge, the only study that targeted the problem of model transferability explicitly was that of MacDougall and Flowers (2011) who tested the spatial and temporal transferability of a distributed energy- and mass-balance model for two ablation seasons on two subArctic glaciers. They found that transfer in space and time can lead to large errors in modeled mass balance. Even applying the same model at a different location or time within a single glacier results in differences in the rootmean-square difference (RMSD) between measured and modeled mass balance for one summer season of up to $30 \%$ of the measured amplitude (MacDougall and Flowers, 2011). The magnitude of such errors is unknown for glaciers 


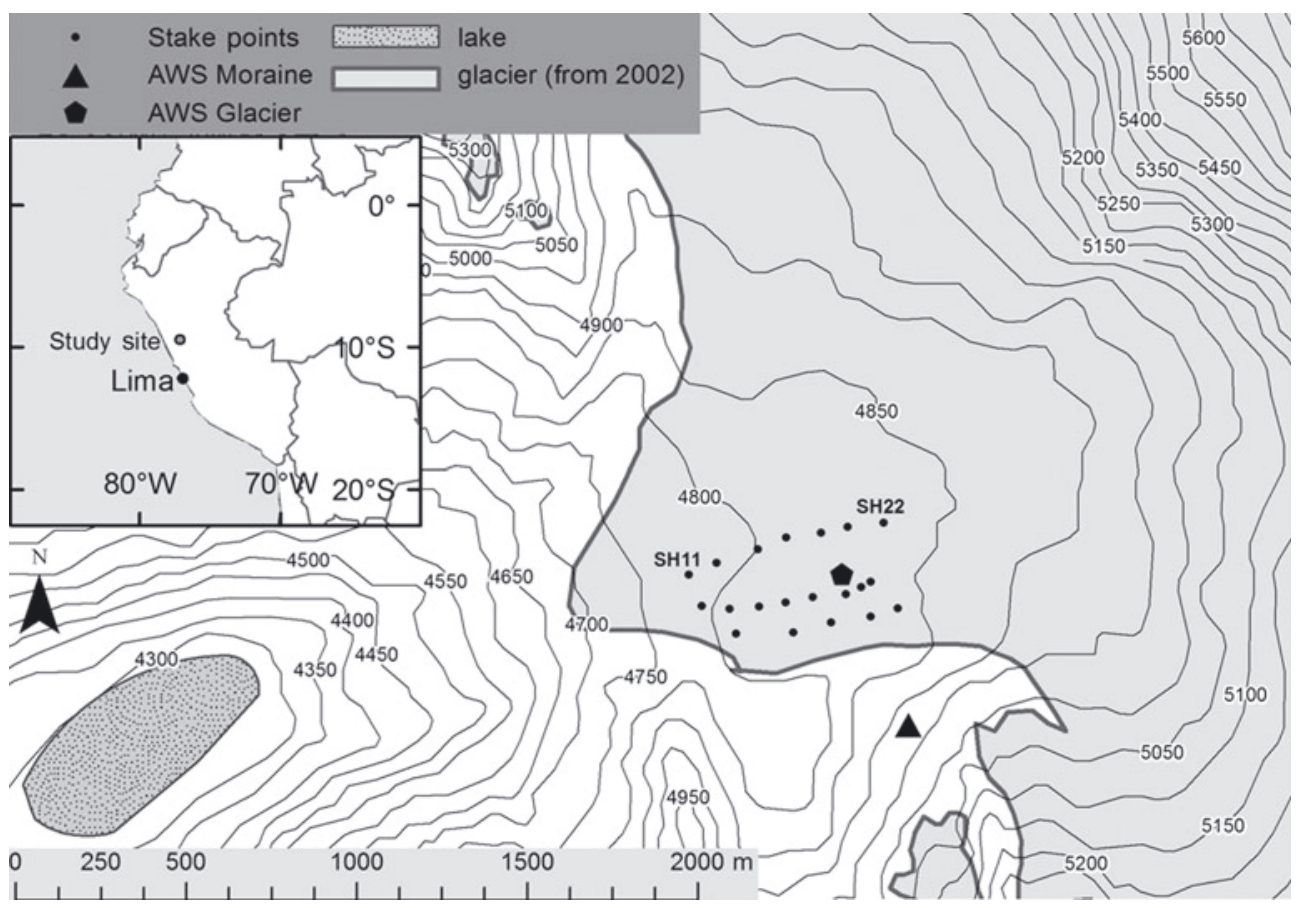

Fig. 1. Terrain, glacier extent, AWS locations and stake measurement points on Glaciar Shallap, Peru. The reference stake points SH11 and SH22 used in this study are labeled. Extrapolation of the mean vertical gradient of surface height change (Fig. 3) at the measured stakes suggests that the equilibrium-line altitude for the two years studied lies 50-100 m above the highest stake position.

in the Peruvian Andes, where both glacier field data and mass-balance modeling studies are limited.

The goals of this study are therefore to (1) evaluate the performance of a process-based mass-balance (MB) model applied to a single point location on a tropical Andean glacier when driven by a combination of measured meteorological inputs and optimized model parameters and to (2) test the parameter transferability of the processbased MB model for two nearby points (distance $<800 \mathrm{~m}$ horizontally and $<60 \mathrm{~m}$ in altitude) in the ablation zone of this glacier in order to determine characteristic model errors associated with the transfer.

\section{STUDY AREA AND METHODS}

Glaciar Shallap (Fig. 1) is located in the outer tropics, on the western side of the Peruvian Cordillera Blanca $\left(9^{\circ} 29^{\prime} \mathrm{S}\right.$, $-77^{\circ} 20^{\prime} \mathrm{W}$ ). A $50 \mathrm{~m}$ resolution digital elevation model (DEM) derived from satellite data from 2002 (Georges, 2004) indicates that the total glacier area was $7.035 \mathrm{~km}^{2}$, spanning an elevation range of 4680-5910 m a.s.l., with $>50 \%$ of the glacier surface area lying between 4800 and $5200 \mathrm{~m}$. The glacier runoff drains into the Río Santa in Huaraz. The local climate is characterized by muted seasonal variations in temperature but strong seasonal variations in precipitation, with a wet season typically lasting from October to April and a dry season from May to September (e.g. Juen and others, 2007). Ablation and accumulation can both occur throughout the year, although accumulation rates are peak during the wet season (Kaser, 2001).

\subsection{Measurements}

\subsubsection{Stake measurements}

Measurements of glacier surface height change were made by the Unidad de Glaciología y Recursos Hídricos (UGRH) of the Peruvian Instituto Nacional de Recursos Naturales
Ancash (INRENA) with a network of 20 stakes in part of the ablation zone of Glaciar Shallap from August 2006 until August 2008. Consequently, these two hydrological years are the focus of our study. The horizontal locations of the stakes were determined from GPS measurements made during the stake surveys of 2006 and 2007, and, in the absence of adequate field data, representative elevation, surface slope and aspect for each stake point were taken to be the mean of the 2002 DEM gridcell containing the stake (Georges, 2004). The mean elevation of each DEM gridcell was within $\pm 7 \mathrm{~m}$ of the GPS measurements. Surface height change at all stakes was measured over 21 intervals ranging from 14 to 64 days in length (see Fig. 4, further below). Unfortunately, information on snow depth was recorded only sporadically and snow density was not recorded at all. Thus, the stake measurements provide only relative surface height change and cannot be converted to mass or water equivalent height change. However, as the glacier surface was snow-free at the beginning and end of each hydrological year, annual surface height change ( $\mathrm{mm}$ ice eq.) can be obtained. Surface height readings from stakes $\mathrm{SH} 11$ $(4758 \mathrm{~m})$ and $\mathrm{SH} 22(4816 \mathrm{~m})$ are used as reference data (Fig. 1) against which we evaluate the MB model and the parameter transferability in space and time. These stakes were chosen because they encompass the widest elevation range possible along the central flowline within the ablation zone, while having comparable surface slope, aspect and sky view factors. In both years the cumulative values at $\mathrm{SH} 11$ and $\mathrm{SH} 22$ are similar to the neighboring points, and the annual vertical gradient in surface height change between $\mathrm{SH} 11$ and $\mathrm{SH} 22$ is close to the mean gradient (Fig. 3, further below). Thus these two stakes are ideal for examining model transfer within the ablation zone as the impact of topographic factors can be ignored, and annual mass balance at both stakes is representative for the local surface height change gradient. 
Table 1. Details of all sensors and measurement specifications at $A W S_{M}$ and $A W S_{G}$, with sensor height in parentheses and nominal accuracy according to the manufacturer

\begin{tabular}{|c|c|c|}
\hline Variable & $\mathrm{AWS}_{\mathrm{M}}$ & $\mathrm{AWS}_{\mathrm{G}}$ \\
\hline Temperature $\left({ }^{\circ} \mathrm{C}\right)$ & Vaisala $\mathrm{HMP} 4 \mathrm{C}^{\dagger}(2 \mathrm{~m}) \pm 0.2^{\circ} \mathrm{C}$ & Vaisala HMP45C $(2 \mathrm{~m}) \pm 0.2^{\circ} \mathrm{C}$ \\
\hline Relative humidity (\%) & Vaisala HMP45C ${ }^{\dagger}(2 \mathrm{~m}) \pm 2 \%$ & Vaisala HMP45C (2 m) $\pm 2 \%$ \\
\hline Wind speed $\left(\mathrm{m} \mathrm{s}^{-1}\right)$ & R.M. Young/05103 (2 m) $\pm 0.3 \mathrm{~m} \mathrm{~s}^{-1}$ & R.M. Young/05103 $(2 \mathrm{~m}) \pm 0.3 \mathrm{~m} \mathrm{~s}^{-1}$ \\
\hline Wind direction $\left({ }^{\circ}\right)$ & R.M. Young/05103 (2 m) $\pm 3^{\circ}$ & R.M. Young/05103 $(2 \mathrm{~m}) \pm 3^{\circ}$ \\
\hline Incoming shortwave rad. $\left(\mathrm{W} \mathrm{m}^{-2}\right)$ & Schenk Star $8101(2 \mathrm{~m}) \pm 3 \%$ & Kipp \& Zonen CG3 (2 m) $\pm 5 \%$ \\
\hline Reflected shortwave rad. $\left(\mathrm{W} \mathrm{m}^{-2}\right)$ & & Kipp \& Zonen CG3 $(2 \mathrm{~m}) \pm 5 \%^{\star}$ \\
\hline Incoming longwave rad. $\left(\mathrm{W} \mathrm{m}^{-2}\right)$ & & Kipp \& Zonen CMP3 (2 m) $\pm 10 \%$ \\
\hline Outgoing longwave rad. $\left(\mathrm{W} \mathrm{m}^{-2}\right)$ & & Kipp \& Zonen CMP3 $(2 \mathrm{~m}) \pm 10 \%$ \\
\hline Relative surface height change* $(\mathrm{m})$ & & Campbell Ultrasonic SR50 $\pm 1 \mathrm{~cm}$ \\
\hline Precipitation (mm) & Ott Pluvio Precipitation gauge $\pm 1 \%$ & \\
\hline
\end{tabular}

*Surface height change driven by climatic mass balance. ${ }^{\dagger}$ Artificially ventilated until 2009. ${ }^{\star}$ For daily totals.

\subsubsection{Automatic weather stations}

Between 2002 and 2012 an automatic weather station (Fig. 1; AWS Moraine, hereafter AWS $\mathrm{AW}_{\mathrm{M}}$ ) was operated on the south moraine of Glaciar Shallap, $150 \mathrm{~m}$ south of the stake measurement zone at $4950 \mathrm{~m}$ a.s.l. All measured variables and sensors are listed in Table 1. Data are available from January 2006 until November 2009 without gaps. Hourly data from this station were used as input for our MB model as the measurements span the period of the available stake measurements that define the study period.

Since July 2010 a second AWS (Fig. 1; AWS Glacier, hereafter $\mathrm{AWS}_{\mathrm{G}}$ ) has been operating on the glacier surface at $4796 \mathrm{~m}$ within the stake reading zone (Section 2.1.2). Data from this station were used to (1) determine statistical transfer functions between the moraine station and the glacier station, (2) develop an incoming longwave radiation parameterization and (3) assign some model parameters pertaining to the glacier surface (Table 6 in the Appendix). A data gap in all records occurred between February and April 2012 when water entered the logger box and measurements ceased. Although the surface height was measured at this station with a sonic ranger (SR50), these data are not used here because, despite frequent maintenance, strong ablation over the whole measurement period resulted in both turning and tilting of the sensor.

Concurrent temperature, humidity and wind-speed data from both stations from July 2011 to February 2012 (214 days) were used to develop a local transfer function for air temperature from $\mathrm{AWS}_{\mathrm{M}}(4950 \mathrm{~m})$ to $\mathrm{AWS}_{\mathrm{G}}(4796 \mathrm{~m})$. Best results were obtained by the multiple regression

$$
\dot{T}_{\mathrm{G}}=\mathrm{a}_{0}+\mathrm{a}_{1} \cdot T_{\mathrm{M}}+\mathrm{a}_{2} \cdot \mathrm{RH}_{\mathrm{M}}+\mathrm{a}_{3} \cdot \mathrm{ws}_{\mathrm{M}},
$$

where $\dot{T}_{\mathrm{G}}$ is the calculated hourly air temperature at $\mathrm{AWS}_{\mathrm{G}}$ $T_{M}, \mathrm{RH}_{\mathrm{M}}$ and $\mathrm{wS}_{\mathrm{M}}$ are the air temperature, relative humidity and wind speed measured at $\mathrm{AWS}_{M}$ and the coefficients $a_{0-3}$ are $-1.825,0.925,0.022$ and 0.191 respectively. Calibration of the regression coefficients was done using all available values. However, as we use this transfer function beyond our calibration period, we evaluated our results by applying a leave-one-out cross-validation (Hofer and others, 2010; Wilks, 2011), taking into account autocorrelation of the time series, to obtain an upper limit for the RMSD between measured and calculated values.

This was done by first calculating the hourly anomalies $\Delta T, \Delta \mathrm{RH}$ and $\Delta \mathrm{ws}$ with respect to the mean daily cycle of the entire period. Then, for each hourly value, we calculated a multiple regression based on all other values, except those within the autocorrelation timescale $(\sim 1$ week, $|r|<0.2)$. This leads to 4538 regression value estimates, and a reconstructed time series of the same length, where each value was derived independently of the measured value. The performance of this time series therefore provides a reference for the error magnitude of the transfer function that can also be expected outside the calibration period. The resulting RMSD between measured and calculated temperature anomalies is $0.76^{\circ} \mathrm{C}$ whereas the standard deviation of the measured anomalies is $1.2^{\circ} \mathrm{C}$. These results indicate that the transfer function is robust, and for our study site has greater skill than constant linear temperature gradients in the range -0.4 to $-0.9^{\circ} \mathrm{C}(100 \mathrm{~m})^{-1}$ which had $\mathrm{RMSD}>1^{\circ} \mathrm{C}$. Vapor pressure (e) on the glacier was computed from $\mathrm{RH}_{M}$ using $\dot{T}_{\mathrm{G}}$ as an input. The RMSD between e calculated with $T_{\mathrm{M}}$ and $\dot{T}_{\mathrm{G}}$ is $<0.2 \mathrm{hPa}$ and the difference between the mean values is $<0.1 \mathrm{hPa}$.

\subsection{Energy- and mass-balance model}

To calculate the relative surface height change (driven by climatic mass balance) for the two points on the glacier, we applied an energy-balance-based MB model. The model is described in detail elsewhere (Mölg and others 2008, 2009a, 2012), so here we present only a concise overview. The model was run in point mode at hourly time-steps for the period 1 June 2006 to 27 August 2008, with a 3 month spinup period in order to develop appropriate initial snow conditions. Values of temperature transferred to the glacier (Section 2.1.1), and hourly measurements of relative humidity, wind speed, solar radiation and all-phase precipitation at $\mathrm{AWS}_{\mathrm{M}}$ serve as input. Values for the 24 parameters used in the model are given in Table 6 in the Appendix.

The model calculates accumulation as the sum of solid precipitation, surface water deposition and refreezing of liquid water in the snowpack. Solid precipitation is extracted from all phase precipitation by assuming a linear interpolation of the percentage of liquid and solid precipitation between an upper temperature threshold, above which all precipitation is liquid, and a lower temperature threshold, below which all precipitation is solid (Table 6). Total modeled ablation includes surface melt, sublimation and subsurface melt. Surface melt and sublimation are based on the surface energy balance (all terms in $\mathrm{W} \mathrm{m}^{-2}$ ):

$$
S \downarrow(1-\alpha)+L \downarrow+L \uparrow+Q_{\mathrm{S}}+Q_{\mathrm{L}}+Q_{\mathrm{C}}+Q_{\mathrm{PS}}+Q_{\mathrm{RPC}}=F,
$$




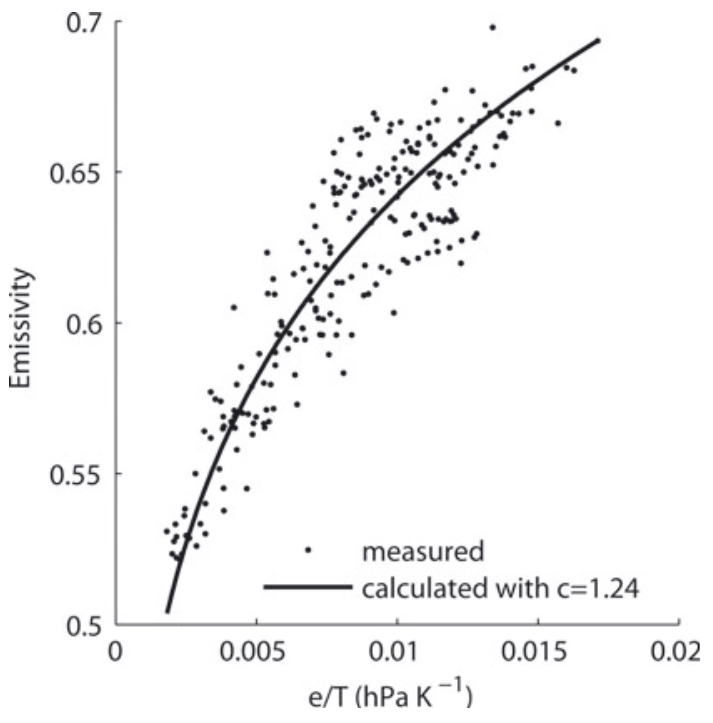

Fig. 2. Atmospheric emissivity versus the ratio of vapor pressure (e) to temperature $(T)$ recalculated after Sicart and others (2010) for hourly values for five clear-sky days from 5 to 10 August 2010.

where $S \downarrow$ is the incoming shortwave radiation, $\alpha$ is the broadband surface albedo, $L \downarrow$ and $L \uparrow$ are the incoming and outgoing longwave radiation, $Q_{\mathrm{S}}$ and $Q_{\mathrm{L}}$ are the sensible and latent heat fluxes, $Q_{\mathrm{C}}$ is the conductive heat flux, $Q_{\mathrm{PS}}$ is the part of shortwave radiation that penetrates into the subsurface, $Q_{\mathrm{RPC}}$ is the heat flux from precipitation and $F$ is the residual energy flux. If $F$ is positive and surface temperature is $273.15 \mathrm{~K}$, the melt energy $Q_{M}$ equals $F$.

Absorbed solar radiation is the main energy source for ablation on tropical glaciers (e.g. Mölg and Hardy, 2004; Sicart and others, 2005). The original model computes $S \downarrow$ from theoretical considerations in conjunction with a cloud cover factor (Mölg and others, 2009b), but to minimize the use of input parameterizations we chose measured $S \downarrow$ as model input. To extrapolate the horizontal radiation measurements at $\mathrm{AWS}_{M}$ to the stake locations, we first separated $S \downarrow$ into its direct and diffuse components following Hock and Holmgren (2005) and then calculated $S \downarrow(x, y)$ for the glacier gridpoints containing the two evaluation stakes accounting for topographic shading, slope and aspect. Reflected shortwave radiation from the surroundings is not considered because the sky-view factors for the stake measurement zone at Glaciar Shallap are high, and the southern slopes are usually exposed dark rock with infrequent snow cover.

The albedo module within the MB model is based on the scheme of Oerlemans and Knap (1998) which calculates surface albedo as a function of fresh snow albedo, firn albedo, ice albedo, a timescale and a depth scale. In our model, the daily threshold used to determine a snowfall event in the original model (Oerlemans and Knap, 1998) is replaced with a threshold applied to the sum of consecutive hours with snowfall (parameter P24 in Table 6). For example, if there are five consecutive hours with a snowfall rate of $0.3 \mathrm{~cm} \mathrm{~h}^{-1}$, the sum is $1.5 \mathrm{~cm}$ and the snow albedo will be set to the fresh snow value as soon as the threshold value is exceeded.

$L \downarrow$ was calculated following the method of Sicart and others (2010) for Glaciar Zongo, Bolivia, using data from $\mathrm{AWS}_{\mathrm{G}}$ to optimize the model for local conditions. The equation for all-sky longwave radiation $L_{0} \downarrow$ then reads

$$
L_{0} \downarrow=c\left(\frac{e}{T}\right)^{1 / 7} \cdot\left(1.44-\tau_{\mathrm{atm}} 0.53\right) \sigma T^{4},
$$

where $c$ is a coefficient for clear-sky emissivity (1.24; see Fig. 2), $T$ is the air temperature, $\tau_{\text {Atm }}$ is atmospheric solar transmissivity and $\sigma$ is the Stefan-Boltzmann constant. $L \downarrow$ is then calculated by considering the sky view factor and the emission of the surrounding terrain (Sicart and others, 2011, equation 11). A comparison with measured $L \downarrow$ based on 7989 hourly values shows that the fit yields a RMSD of $25 \mathrm{~W} \mathrm{~m}^{-2}$ and a $r^{2}$ of 0.59 . For daily means RMSD is $16 \mathrm{~W} \mathrm{~m}^{-2}$ and $r^{2}$ is 0.81 , comparable to the values obtained by Sicart and others (2010). $L \uparrow$ is calculated from surface temperature following the Stefan-Boltzmann law and assuming emissivity to be unity. Surface temperature change for every time-step is calculated from $F$ which warms or cools a defined layer thickness due to energy storage change (Mölg and others, 2009a).

The computation of the turbulent fluxes $Q_{\mathrm{S}}$ and $Q_{\mathrm{L}}$ is based on the bulk method, with the option of using a choice of two different stability correction functions (Table 6 in Appendix). Characteristic surface roughness lengths for snow and ice were adopted from published literature (Table 6). The subsurface module solves the thermodynamic energy equation numerically on a vertical grid with 14 layers at depths of $0.09,0.18,0.3,0.4,0.5,0.6,0.8,1,1.4,1.8$, $2.2,2.5$ and $3 \mathrm{~m}$. At the bottom boundary we prescribe a constant temperature of $272 \mathrm{~K}$ because for the local climate we assume ice temperatures to be close to the pressuremelting point in the ablation zone throughout the year. The module considers $Q_{\text {PS }}$ as a fraction (values in Table 6) of net shortwave radiation that penetrates the subsurface and is attenuated exponentially with depth (Bintanja and Van den Broeke, 1995). $Q_{C}$ is determined by the temperature difference between the surface and the first layer in the subsurface. As observed temperatures during precipitation are always close to $0^{\circ} \mathrm{C}, Q_{\mathrm{RPC}}$ is not considered here.

As noted by Mölg and others (2012), the model accounts for densification of the snowpack through compaction and refreezing of liquid water. This leads to a physically based modeled surface height change that we use here as the metric to be evaluated against the available measurements of surface height change at the stakes. The 24 model parameters (Table 6) can be varied within their physically meaningful ranges (e.g. Mölg and others, 2012). Surface albedo constants (Oerlemans and Knap, 1998) were estimated from $\mathrm{AWS}_{\mathrm{G}}$ measurements and lie within the range of previously reported values (e.g. Klok and Oerlemans, 2002; Mölg and others, 2008; Sicart and others, 2011). All other parameter ranges were chosen on the basis of previously published values and these, and their sources, are specified in Table 6.

\subsection{Model evaluation method}

The relative mass-balance sensitivity to each of the 24 parameters was found by computing (1) a standard model run for each stake position over the two consecutive hydrological years using median parameter values and (2) two further model runs for the upper and lower limit value of each parameter (Table 6 in Appendix) while keeping the other parameters constant at the median range values. We then computed the difference in cumulative calculated mass-balance values over the entire period 


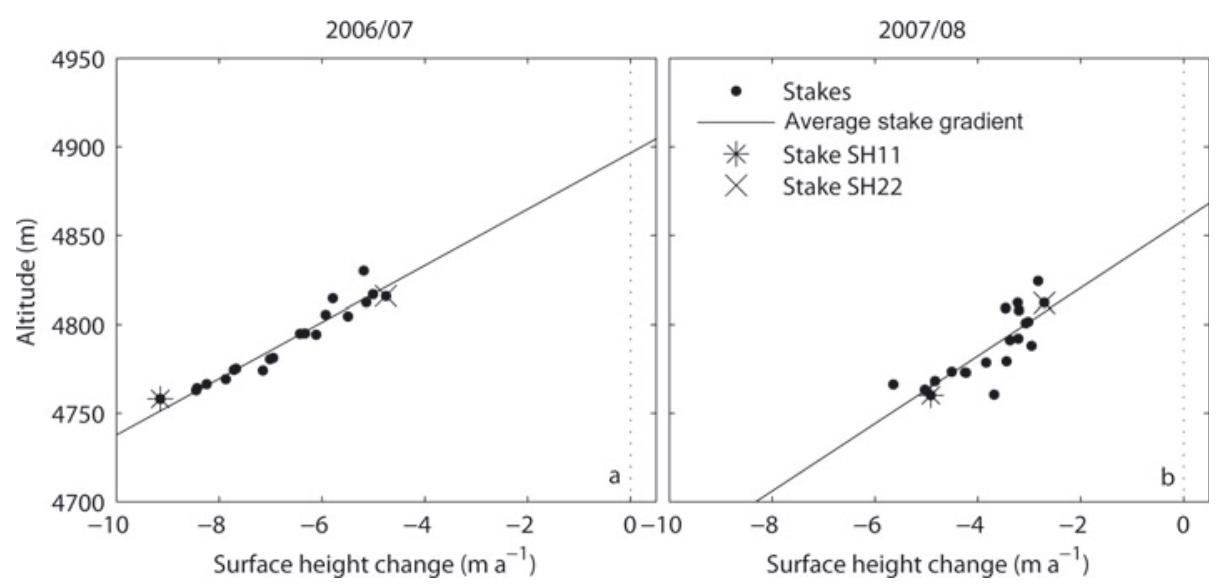

Fig. 3. Cumulative relative surface height change measured at 20 stake points and average linear vertical gradient within the stake area for each year.

between the two perturbed runs and the standard run. As all calculated model sensitivities are influenced by the chosen median value and range of the parameters, this simple test yields only estimates of the relative mass-balance sensitivity of our model to each parameter.

The parameters that resulted in a cumulative massbalance change of more than $\pm 5 \%$ in this single parameter sensitivity study were P3, P4, P5, P12, P15, P19, P20, P21, P22, P23 and P24 (Table 6; Fig. 5, further below). Within 1000 simulations for each of the two evaluation stake locations in each hydrological year, these 11 parameters were assigned randomly from a uniform distribution of their respective prescribed ranges (Table 6). Following Mölg and others (2012), results of a model run, and its associated combination of parameters, are accepted if the RMSD between modeled and measured relative surface height at each stake reading is $<10 \%$ of the measured cumulative amplitude and the deviation is $<10 \%$ at the end of the time series. The best parameter combination (BPC) of the accepted runs is the one which results in the model output with the smallest RMSD between measured and modeled surface height. The model transferability in space and time is then tested by comparing RMSD and annual deviations between the results of different model runs and the measurements for each period.

\section{RESULTS AND DISCUSSION}

\subsection{Characteristics of measured surface height change}

Annual surface point mass balance in ice equivalent can be determined directly from all stake measurements, as the surface at the stakes at the beginning and end of each hydrological year was snow-free. Cumulative surface mass balance at the points was more negative in the first year, with annual values of -9.15 and $-4.75 \mathrm{~m}$ ice eq. at $\mathrm{SH} 11$ and $\mathrm{SH} 22$ respectively, than in the second year, for which cumulative surface mass balance was -5.65 and $-2.7 \mathrm{~m}$ ice eq. at $\mathrm{SH} 11$ and $\mathrm{SH} 22$ respectively (Fig. 3). Less negative mass balance in the second year is accompanied by a $127 \mathrm{~mm}$ higher annual precipitation sum and a $0.6^{\circ} \mathrm{C}$ lower annual mean temperature at $\mathrm{AWS}_{M}$ (Table 2). Mean vertical surface mass-balance gradients within the stake area were very high in both years $\left(6.3\right.$ and $5.2 \mathrm{~m}$ ice eq. $(100 \mathrm{~m})^{-1}$, respectively) although the terrain and surface features do not change markedly across this area. Similarly high gradients in surface mass balance within the ablation zone of other tropical glaciers in South America were attributed to strong vertical gradients in snow-cover frequency (Kaser, 2001; Sicart and others, 2007; Fig. 4). It is likely that the large gradient in surface mass balance within the stake measurement zone on Glaciar Shallap is also related to frequently inhomogeneous snow cover within the stake area during both years of our study period.

Mean daily relative surface height change between each measurement at the two reference points (Fig. 4) shows a strong variability for the first year, with two lowering maxima in measurement intervals 1 and 5 and two periods with reduced lowering in the wet season (intervals 3 and 4; intervals 7-9). The periods of reduced surface lowering coincide with the formation of several snowpacks that persisted for several days to weeks and which were also documented in the data of the UGRH (Section 2.1.2). The second year is different because surface lowering was strongly reduced, most likely due to frequent snow cover, between December and April (intervals 16-20) at both stakes. Strong surface lowering therefore only occurred in the dry season at the beginning and at the end of the second year (intervals 13 and 21). To support the argument about the general influences of snow-cover patterns, modeled snow depth is also shown in Figure 4. Although modeled snow depth is not always consistent with the measured surface height change, it provides an indication of the timing of snow-cover events that influenced the surface height change over the study period.

Table 2. Annual means or sum of model input for both hydrological years (intervals 1-12 and intervals 13-21 in Fig. 4) recorded by $\mathrm{AWS}_{\mathrm{M}}$. $T$ is the temperature, $\mathrm{vp}$ the vapor pressure, $\mathrm{RH}$ the relative air humidity, ws the wind speed, $S \downarrow$ the incoming shortwave radiation and $P$ the precipitation

\begin{tabular}{lccccc}
\hline Year & $T$ & vp (RH) & ws & $S \downarrow$ & $P($ sum $)$ \\
& ${ }^{\circ} \mathrm{C}$ & $\mathrm{hPa}$ & $\mathrm{m} \mathrm{s}^{-1}$ & $\mathrm{~W} \mathrm{~m}^{-2}$ & $\mathrm{~mm}$ w.e. \\
\hline $2006 / 07$ & 1.6 & $4.9(73 \%)$ & 2.5 & 214 & 1617 \\
$2007 / 08$ & 1.0 & $4.8(73 \%)$ & 2.5 & 218 & 1744 \\
\hline
\end{tabular}




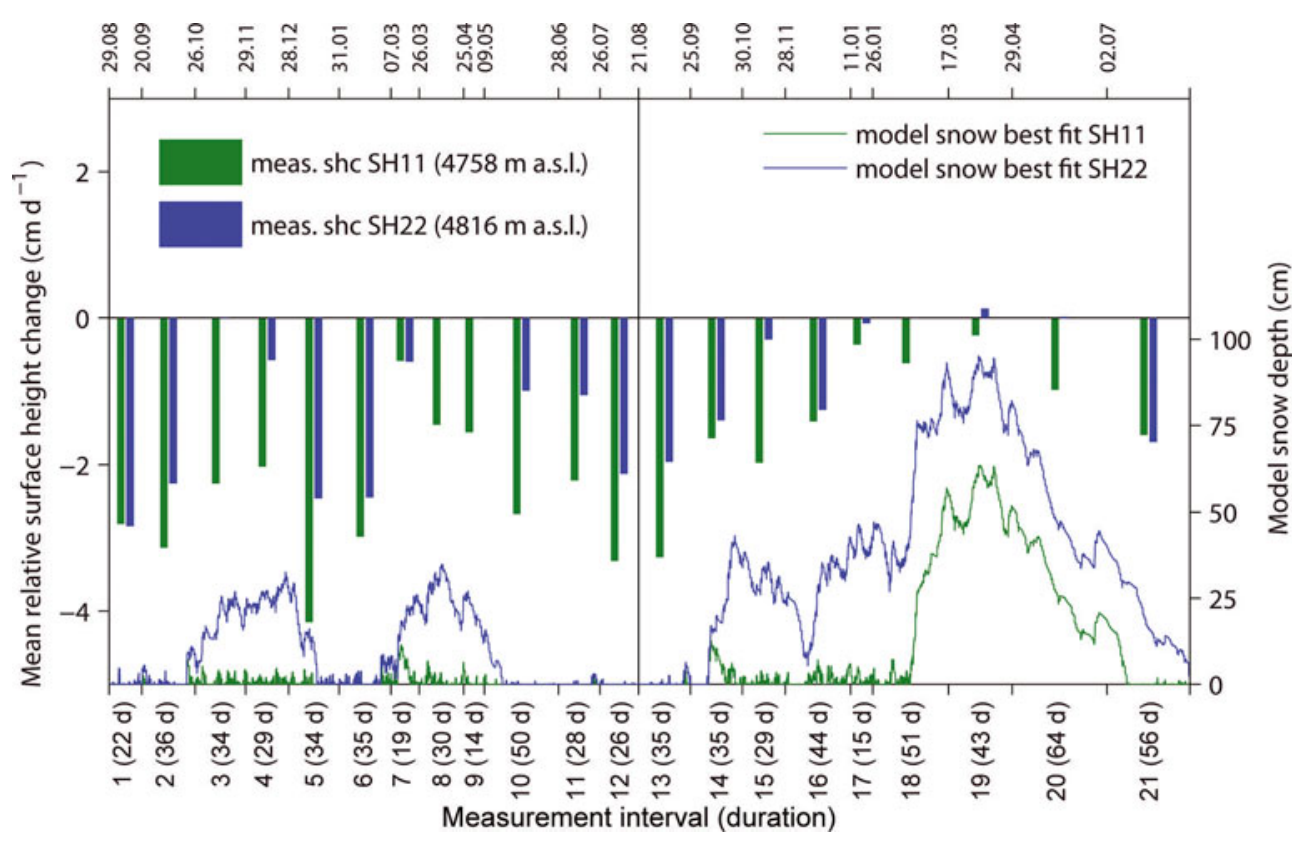

Fig. 4. Bars indicate the mean daily relative measured surface height change (meas. shc) for each measurement interval at stake points SH11 (green) and $\mathrm{SH} 22$ (blue). At SH22 the measured surface height change is zero or close to zero for several intervals. Solid lines show modeled snow depth for model runs using the optimized parameter sets (e 3.3) for SH11 (green) and SH22 (blue). Measurement intervals are denoted in date form (dd.mm) along the upper axis and by numbers along the bottom axis, with the duration of each interval $(\mathrm{d}=$ days $)$ in parentheses.

\subsection{Energy-balance components and parameter sensitivity}

The modeled energy-balance components (Table 3) show that at Glaciar Shallap net shortwave radiation is the greatest source of energy to the glacier surface, as has previously been well documented for other tropical glaciers (e.g. Wagnon and others, 1999; Favier and others, 2004a; Francou and others, 2004; Mölg and Hardy, 2004; Nicholson and others, 2012). Sensible heat flux is the next largest source of energy to the glacier but on average reaches a maximum of only $10 \%$ of the energy contribution of shortwave radiation. Only $30-40 \%$ of the net shortwave energy receipt is offset by the negative net longwave flux, and although a portion of the net shortwave penetrates the glacier surface and warms the subsurface, surface melting consumes the largest proportion of the net shortwave energy contribution at both stake locations. The main differences in the modeled mean energy-balance components at the two stake locations are in the reflected and penetrating shortwave components, which indicates that the snow-cover conditions at the two stake locations were different over the course of the study period, with $\mathrm{SH} 22$ having on average a higher surface reflectance than $\mathrm{SH} 11$.

As a consequence of the dominance of net shortwave in the surface energy balance, results of the sensitivity tests for
SH11 and SH22 (Fig. 5) show that model output is most sensitive to parameters that are related to the shortwave energy budget. These are especially ice albedo (P19), fresh snow albedo (P20), old snow albedo (P21), albedo timescale (P22), albedo depth scale (P23) and the snow event threshold for albedo (P24). In addition, modeled mass balance is sensitive to parameters that affect the amount of solid precipitation (P3 and P4), which also impact net shortwave radiation, as well as parameters that affect the development of the snowpack and the penetration of shortwave radiation into the snow (P12 and P15). The importance of snowpack- and albedo-related parameters to modeled mass balance is in agreement with former studies of glacier energy balance both within and outside the tropics (e.g. Favier and others, 2004b; Mölg and Hardy, 2004; Mölg and others, 2009a, 2012; MacDougall and Flowers, 2011; Sicart and others, 2011). Modeled mass balance also shows moderate sensitivity to the representative layer thickness (P5; Klok and Oerlemans, 2002) due to its impact on simulated surface temperature (Mölg and others, 2009b).

By contrast, mass-balance sensitivity to parameters relevant for turbulent fluxes (P6-P11 in Table 6 in the Appendix) is generally low. Comparison of the data collected at $\mathrm{AWS}_{\mathrm{M}}$ and $\mathrm{AWS}_{\mathrm{G}}$ indicates that this is unlikely to be because the conditions at the glacier surface are not well represented by the input data (Section 2.1.2). It is

Table 3. Means of modeled energy fluxes $\left(\mathrm{W} \mathrm{m}^{-2}\right)$ for the standard run for the period 29 August 2006 to 27 August 2008. Abbreviations are explained in Section 2.2

\begin{tabular}{|c|c|c|c|c|c|c|c|c|c|}
\hline Location & $S \downarrow$ & $S \uparrow$ & $L \downarrow$ & $L \uparrow$ & QPS & $Q_{S}$ & $Q_{\mathrm{L}}$ & $Q_{C}$ & $Q_{M}$ \\
\hline $\mathrm{SH} 11$ & 211 & -86 & 274 & -311 & -22 & 13 & -13 & 5 & -66 \\
\hline
\end{tabular}




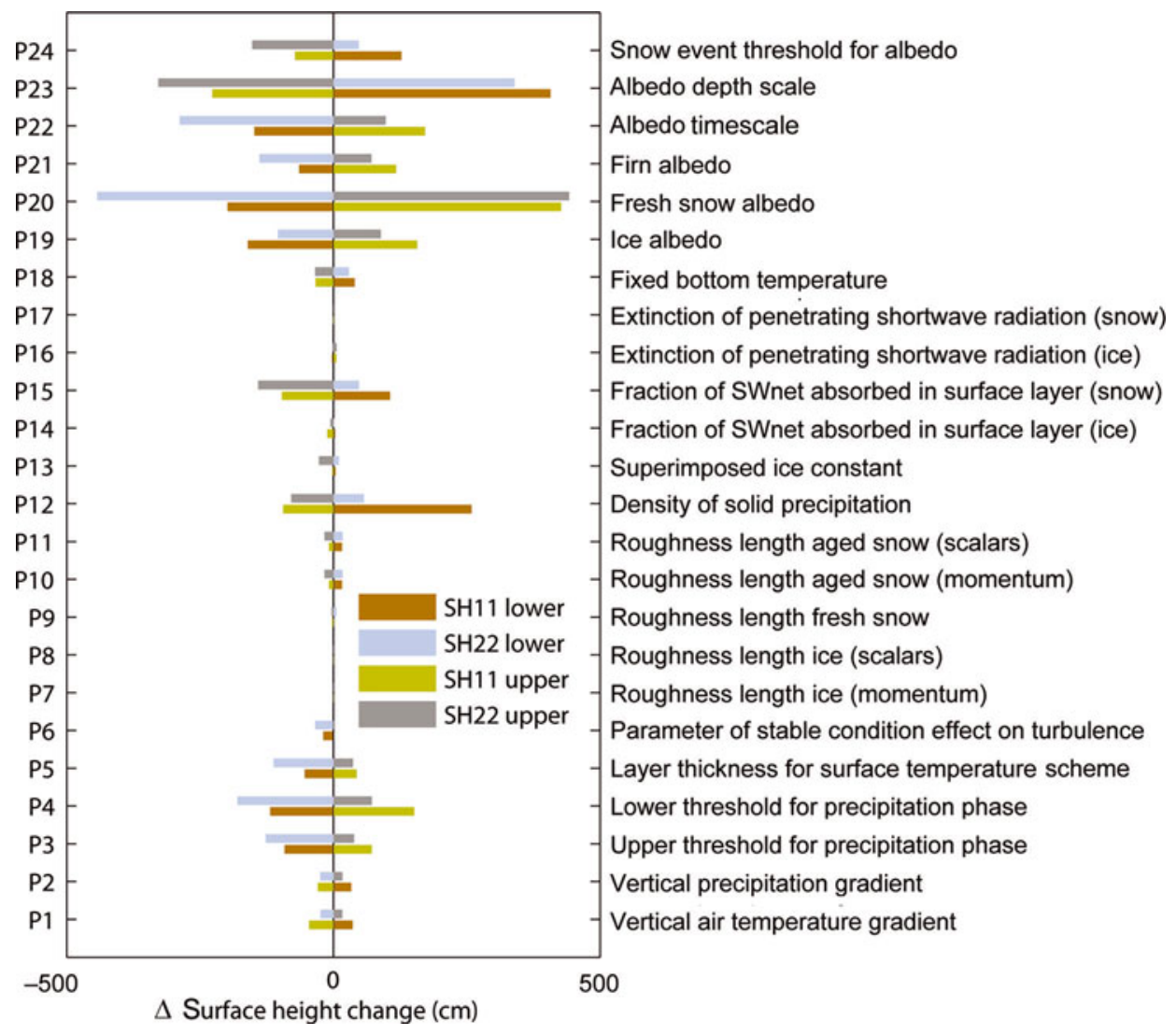

Fig. 5. Difference in relative surface height change of model output for lower/upper limit of each model parameter value within the defined range (Table 6 in Appendix) subtracted from the standard run with median values for all parameters.

possible that the sensitivity to the turbulent fluxes is reduced because the sensible and latent heat flux have different signs during the observation period (Table 3); however, even the direct comparison of the mean turbulent fluxes from the standard run (median parameter values) with the means from the sensitivity runs for parameters $\mathrm{P} 6-\mathrm{P} 11$ shows maximum absolute differences of $<1 \mathrm{~W} \mathrm{~m}^{-2}$. For $98 \%$ of the hourly values the absolute differences are $<10 \mathrm{~W} \mathrm{~m}^{-2}$. In this study, temperature and precipitation gradients have little impact on modeled results, but this is because our stake sites are separated by $<60 \mathrm{~m}$ in altitude.

Model sensitivity to the selected parameters differs slightly between the two model points (Fig. 5). At SH11, snow cover is less frequent and usually thinner. Therefore model sensitivity to ice albedo (P19) is higher. In the case of the shallow snow cover, both parameters P12 (density of falling snow) and P23 (albedo depth scale) have an enhanced effect on the modeled surface height change. At SH22 the sensitivity to fresh snow albedo (P20) dominates because the surface is snow-covered for more of the study period at this location (Fig. 4).

\subsection{Model performance at point scale}

The results of our simulations described in Section 2.3 are plotted in Figure 6. For SH11, 306 runs passed the criteria for acceptable performance, while at $\mathrm{SH} 22$ only ten parameter combinations produced acceptable model output. The main reason for this difference in the number of accepted model runs is the smaller amplitude in cumulative surface mass balance measured at $\mathrm{SH} 22$. If we use the amplitude of $\mathrm{SH} 11$ to calculate the relative RMSD, 234 runs fulfill the criterion at $\mathrm{SH} 22$. The best model run for $\mathrm{SH} 11$ has a RMSD of $1.5 \%$ $(0.21 \mathrm{~m})$ relative to the measured surface height amplitude. The difference between the cumulative measured $(-14.06 \mathrm{~m})$ and modeled surface height change is $-0.14 \mathrm{~m}$ at the end of the time series. The best model run for $\mathrm{SH} 22$ has a RMSD of $6.4 \%(0.48 \mathrm{~m})$ between measured and modeled surface height, and the difference between measurement $(-7.47 \mathrm{~m})$ and model at the end of the series is $+0.9 \mathrm{~m}$. The parameter values for the best-fit parameter combinations (BPCs) resulting in model runs with the best fit to measured surface height change at both $\mathrm{SH} 11$ and $\mathrm{SH} 22$ (BPCSH11 and BPCSH22 respectively) are listed in Table 4.

Table 4. Best-fit parameter combinations (BPCs) of the model parameters to which modeled mass balance shows the greatest sensitivity in our simulations at stake locations $\mathrm{SH} 11$ and $\mathrm{SH} 22$. The parameter names are listed in Table 6

\begin{tabular}{|c|c|c|c|c|c|c|c|c|c|c|c|}
\hline & P3 & P4 & P5 & P12 & P15 & P19 & P20 & P21 & P22 & P23 & P24 \\
\hline & ${ }^{\circ} \mathrm{C}$ & ${ }^{\circ} \mathrm{C}$ & $\mathrm{cm}$ & $\mathrm{kg} \mathrm{m}^{-3}$ & $\%$ & & & & days & $\mathrm{cm}$ & $\mathrm{cm}$ \\
\hline BPCSH11 & 2.6 & 1.1 & 0.48 & 296 & 0.82 & 0.28 & 0.86 & 0.55 & 7.1 & 5.7 & 1 \\
\hline BPCSH22 & 2.9 & 1.1 & 0.49 & 250 & 0.85 & 0.22 & 0.80 & 0.60 & 7.3 & 2.5 & 1 \\
\hline
\end{tabular}




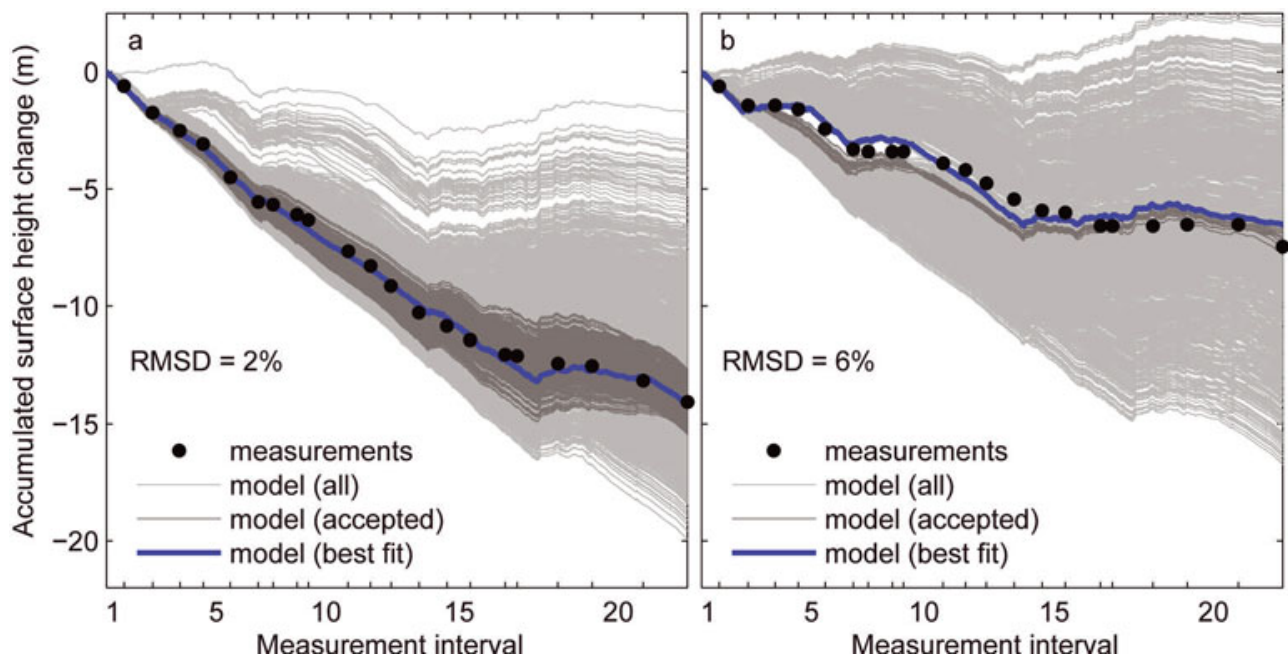

Fig. 6. Comparison of cumulative relative surface height change from stake measurements and 1000 model runs for $\mathrm{SH} 11$ (a) and SH22 (b). Parameters to which modeled mass balance is most sensitive (Section 3.2) are assigned randomly from uniform distributions within defined ranges (Table 6 in Appendix). Accepted runs are those that meet two criteria: (1) RMSD between modeled and measured relative surface height at each stake $<10 \%$ of the measured cumulative amplitude and (2) surface height difference $<10 \%$ at the end of the model run. The best-fit model run is the one with the minimum RMSD between measured and modeled surface height, and the RMSD shown is for the best-fit run.

\subsection{Parameter transferability in space}

In Section 3.3 the model performance was evaluated and BPCs were determined for each of the two stake locations separately. Here we test the parameter transferability in space by applying the BPCs for SH11 to SH22 and vice versa. As the BPCs for the two points are different, the RMSD between model and measurements increases when the parameter values of the other stake location are used. The increase in RMSD compared to the results for the best runs is $4 \%(0.26 \mathrm{~m})$ for $\mathrm{SH} 11$ and $10.3 \%(0.77 \mathrm{~m})$ for $\mathrm{SH} 22$ over the entire period.

At location SH11 (Fig. 7a), when the best parameter combination for $\mathrm{SH} 22$ (BPCSH22) is used, the modeled surface evolution only deviates markedly from that modeled with BPCSH11 in the second year from interval 14, after which surface lowering is reduced until the middle of interval 18. This is due to the smaller albedo depth scale (P23) which keeps surface albedo higher for longer (e.g. Mölg and others, 2008) and therefore reduces the net shortwave energy receipts (Fig. 7c). Subsequently, surface lowering is reduced in both runs until the end of interval 19 and increases again toward the end of the study period. Figure $7 \mathrm{c}$ shows that net shortwave radiation controls the differences in melt energy between the two runs. The additional errors between measurement and model as a result of applying the transferred parameter combination (BPCSH22) instead of the best one (BPCSH11) are $5 \mathrm{~mm}$ ice eq. for year 1 and $735 \mathrm{~mm}$ ice eq. for year 2 .

At location $\mathrm{SH} 22$ the model solutions diverge early in the first year during interval 3 (Fig. 7b). Albedo time series and modeled snow depth show that BPCSH11 cannot reproduce the snow cover that was documented by measurements and caused the strongly reduced surface lowering measured during intervals 4 and 5 . As surface albedo remains low for SH11 settings during this period, the differences in melt energy and ablation between the two runs are large (Fig. 7d). However, from interval 5 on, both runs show a similar pattern of surface height evolution. For the second year, mass balance is overestimated by model runs with both BPCs but the pattern of surface height change produced by the runs is similar, so the differences between the runs are smaller than in the first year. As with $\mathrm{SH} 11$ above, the differences in net shortwave radiation and in the penetrating flux of shortwave radiation dominate the difference in melt energy (Fig. $7 \mathrm{~d}$ ). The additional errors due to the parameter transfer (BPCSH11 instead of BPCSH22) are $1326 \mathrm{~mm}$ ice eq. for year 1 and $542 \mathrm{~mm}$ ice eq. for year 2 .

Overall, Figure $7 \mathrm{c}$ and $\mathrm{d}$ illustrate that the parameter transfer in space primarily alters the net shortwave energy fluxes, and thus different snow-cover patterns evolve $(S \downarrow$ is the same for all runs). As the sum of modeled solid precipitation differed by only $2 \%$, the differences in snowcover patterns are mainly driven by different rates of snow ablation and removal in the model, which are in turn a result of the different combinations of albedo constants. On short timescales (e.g. a few months) these differently modeled patterns can cause very different ablation rates, while on longer (annual) time series the differences can be compensated (e.g. Fig. 7b and d) as evidenced by a tendency for convergence in cumulative melt energy differences and modeled surface height evolution with both BPCs toward the end of the records. For periods with only sporadic snow cover (year 1 at $\mathrm{SH} 11$ ) the results for both parameter combinations are very similar.

\subsection{Parameter transferability in time}

In Section 3.3, we presented model performance with constant parameter combinations for both hydrological years. Here we target parameter transfer in time. Figure 8 and Table 5 show the best runs for each point and each year, and compare them to runs with parameter settings for the same stake but optimized for the other year.

At SH11, Figure 8a and c illustrate that during the first year the modeled energy fluxes are very similar and the model performs well in reproducing measurements with the settings optimized for either year. However, in year 2, the best parameter combination for year 1 (BPCSH11Year1) clearly underestimates surface lowering, so the RMSD becomes large. The different evolution can be explained by the higher surface albedo between intervals 14 and 17 in the second year, which is related to persistent snow cover. 

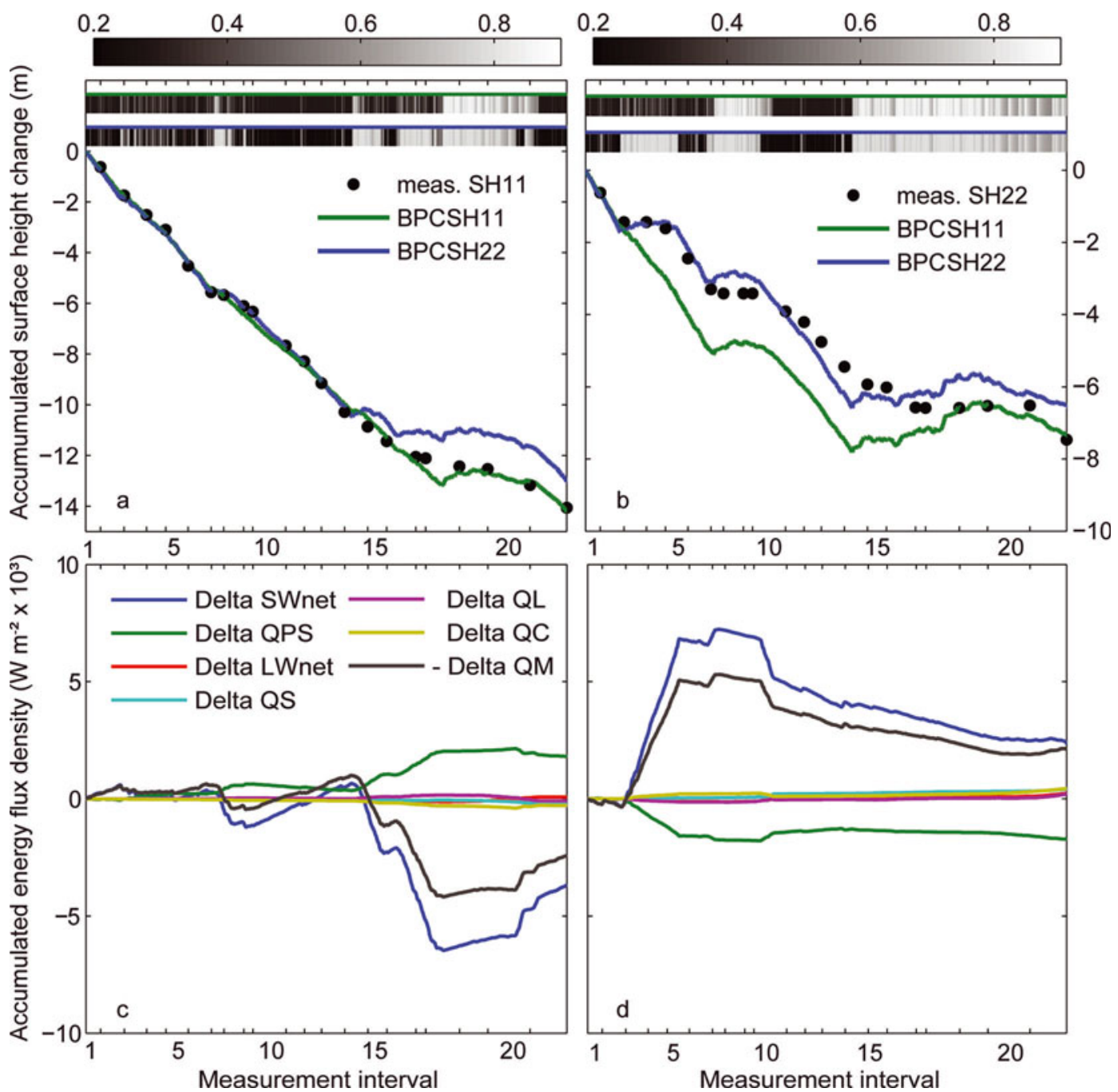

Fig. 7. (a. b) Modeled cumulative relative surface height change from 29 August 2006 to 27 August 2008 with best parameter combinations (BPCs) for each location at SH11 (a) and SH22 (b). Measured values are shown as black dots. Bars at the upper borders of the plots show calculated surface albedo for both runs at hourly time-steps (upper bar is for SH11 run, lower bar for SH22 run). (c, d) Cumulative differences in daily means of energy-balance terms ( $S W_{\text {net }}$ and $\mathrm{LW}_{\text {net }}$ are the net shortwave and net longwave radiation fluxes; the other abbreviations are explained in Section 2.2) for $\mathrm{SH} 11$ (c) and $\mathrm{SH} 22$ (d). In (c) the values calculated with BPCSH11 are subtracted from $\mathrm{BPCSH} 22$, and vice versa in (d). $\Delta \mathrm{SW}_{\mathrm{in}}$ and $\Delta \mathrm{LW}_{\mathrm{in}}$ are zero for all runs. For easier readability, $\Delta Q_{\mathrm{M}}$ is multiplied by -1 (since $Q_{\mathrm{M}}$ in the energy balance is negative by sign convention).

In contrast, the best parameter combination for year 2 (BPCSH11Year2) produces good results for both years. The additional error between measurement and model when using BPCSH11Year2 instead of BPCSH11Year1 for year 1 is therefore only $18 \mathrm{~mm}$ ice eq. For year 2 the additional error (BPCSH11Year1 instead of BPCSH11Year2) is $2069 \mathrm{~mm}$ ice eq.

At $\mathrm{SH} 22$, the BPCs per year at location $\mathrm{SH} 22$ result in much poorer model performance if they are transferred to the other year. This corresponds to a very different evolution of albedo (Fig. 8b), and thus high deviations in net shortwave radiation and melt energy (Fig. $8 \mathrm{~d}$ ) through time in the model output using the different BPCs for each year. The additional error between modeled and measured mass balance due to the parameter transfer in time (BPCSH22Year2 instead of BPCSH22Year1) is $3179 \mathrm{~mm}$ ice eq. for year 1 and $1657 \mathrm{~mm}$ ice eq. for year 2 (BPCSH22Year1 instead of BPCSH22Year2).

As was also found to be the case for parameter transfer in space, parameter transfer in time primarily affects the shortwave energy budget (Fig. 8c and d). As all other fluxes are much smaller (Section 3.2), the differences in net shortwave radiation control the differences in melt energy.

\subsection{Impact of snow cover on model performance and transferability}

Throughout the model experiments in the former sections, model results correspond to the measurements most closely in the first year at $\mathrm{SH} 11$, where snow cover was infrequent (73 out of 357 days with snow depth $>1 \mathrm{~cm}$ in the first year; 212 out of 372 days in the second year) in all model runs. At $\mathrm{SH} 22$, frequent snow cover was experienced throughout both the study years (524 of 729 days with snow depth $>1 \mathrm{~cm}$ ) and model performance was poorer than at SH11. Thus, we can deduce that the model error, and especially that associated with transferability, increases considerably during periods when there are frequent snowfall events and when there is persistent snow cover over several days or weeks in the ablation zone.

This finding is consistent with the fact that modeling snow ablation, and its concomitant surface height evolution, is harder than modeling ice ablation (e.g. Mölg and others 

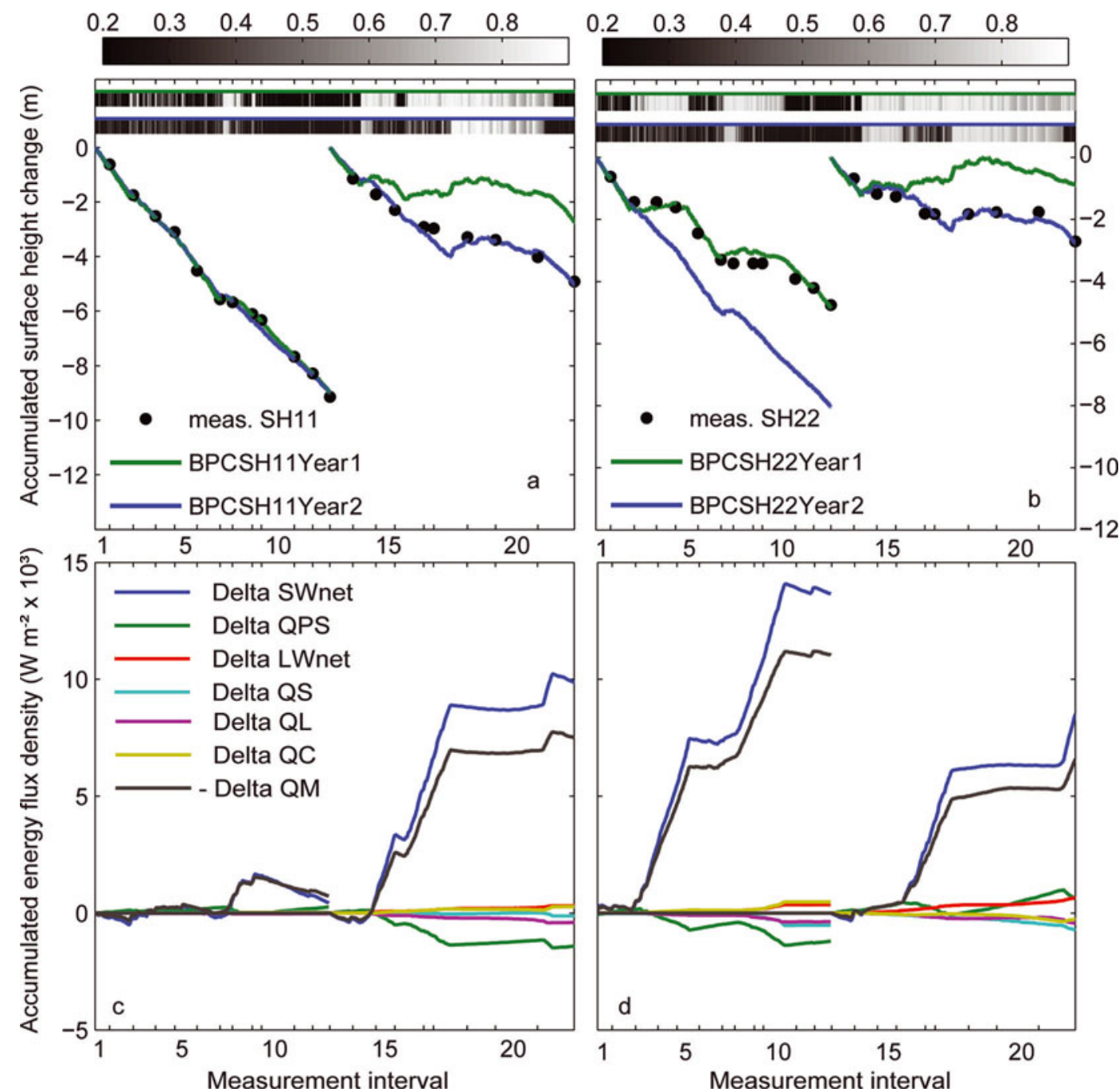

Fig. 8. (a, b) Modeled cumulative relative surface height change with BPC for each year at SH11 (a) and SH22 (b). Measured values are shown as black dots. Bars at the upper borders of the plots show calculated surface albedo for both runs at hourly time-steps (upper bar is for $\mathrm{SH} 11$ run, lower bar for SH22 run). (c, d) Cumulative differences in daily means of energy-balance terms (SW net and LW net are the net shortwave and net longwave radiation fluxes; the other abbreviations are explained in Section 2.2) for SH11 (c) and SH22 (d). In (c) the values calculated with BPCSH11Year2 are subtracted from BPCSH11Year1; in (d) the values calculated with BPCSH22Year2 are subtracted from BPCSH22Year1. $\Delta \mathrm{SW}_{\mathrm{in}}$ and $\Delta \mathrm{LW}_{\text {in }}$ are zero for all runs. For easier readability, $\Delta Q_{\mathrm{M}}$ is multiplied by -1 (since $Q_{\mathrm{M}}$ in the energy balance is negative by sign convention).

Table 5. RMSD between measured and modeled cumulative relative surface height change. Model parameters are optimized for each stake location either for year 1 or year 2. Values in parentheses show the RMSD values expressed as a percentage of the measured surface height change amplitude. Emboldened values indicate the transferred values, while values not in bold show the RMSD when the BPC for the given year and site is used

\begin{tabular}{lcc}
\hline $\begin{array}{l}\text { Applied for point and } \\
\text { year }\end{array}$ & RMSD BPC year 1 & RMSD BPC year 2 \\
& $\mathrm{cm}$ & $\mathrm{cm}$ \\
\hline SH11 year 1 & $9(1.0 \%)$ & $\mathbf{1 5}(\mathbf{1 . 7} \%)$ \\
SH11 year 2 & $\mathbf{1 6 4}(\mathbf{3 3 . 5} \%)$ & $23(4.8 \%)$ \\
SH22 year 1 & $22(4.7 \%)$ & $\mathbf{2 0 5}(\mathbf{4 3 . 1} \%)$ \\
SH22 year 2 & $\mathbf{1 2 3}(\mathbf{4 5 . 5} \%)$ & $17(6.4 \%)$ \\
\hline
\end{tabular}

$2009 b, 2012)$ due to the more complex structure of snow and associated processes (e.g. large density variations, refreezing of meltwater, retention of liquid water), which pose challenges even in detailed snowpack models (Etchevers and others, 2004). In addition, uncertainties in precipitation measurement and in distinguishing between liquid and solid precipitation (e.g. Wagnon and others, 2009) can be a large source of uncertainty in the model accumulation, but we have no adequate data to assess this uncertainty.

The increase of model error in the presence of more frequent snow cover in the ablation zone could also be related to deficiencies in parameterized albedo over snowpacks, associated with our model not capturing the full complexity of the underlying processes. Many published albedo models using simple parameterizations or processresolving snowpack models are still subject to sizeable errors compared to observations (Brock and others, 2000; Etchevers and others, 2004), and in our model it is obvious that as soon as surface albedo shows high fluctuations, model performance decreases and parameter transfer can lead to large errors (Figs $7 \mathrm{a}$ and $\mathrm{b}$ and $8 \mathrm{a}$ and $\mathrm{b}$ ). 


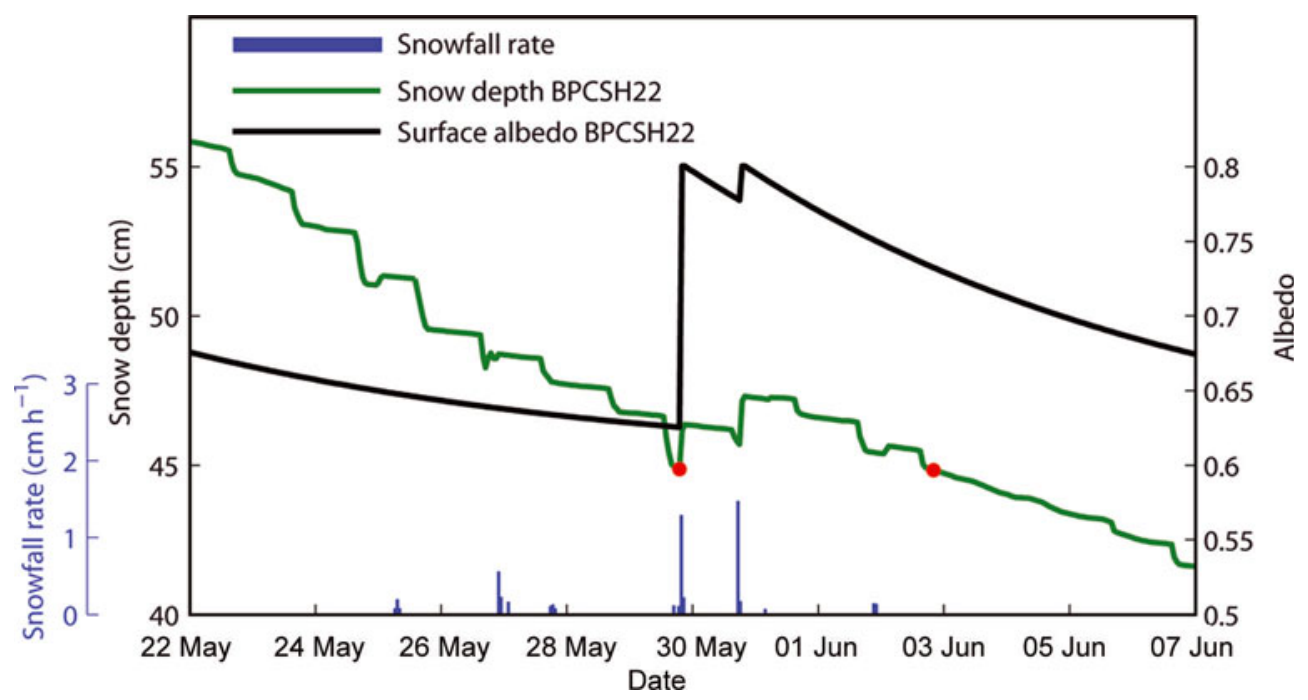

Fig. 9. Calculated snowfall rate, snow depth and surface albedo for BPC for SH22 between 22 May and 5 June 2008 . Red dots indicate model snow depth of $44.8 \mathrm{~cm}$.

An example is plotted in Figure 9, where calculated snowfall intensity, snow depth and surface albedo are shown for 15 days in May/June 2008 for BPCSH22 applied at SH22. Until 29 May, only minor precipitation events were measured and the snowpack thickness and albedo were decreasing steadily. In the evening of 30 May a snowfall event of $1.6 \mathrm{~cm}$ exceeded the albedo threshold value (P24 in Table 4), so model albedo is set to the fresh snow value (P20 in Table 4). A similar event occurred the following day. Then surface albedo decreased until the end of the considered period. However, even though the total amount of fresh snow has ablated in the model before 3 June (right red dot), surface albedo remains much higher than it was before the fresh snow event. That is, the albedo scheme overestimates surface albedo in case of fresh snow falling on older snow if the fresh snow melts away before its exponential ageing reaches the albedo value of the former snow surface. This effect is especially noticeable in the case of frequent light snowfall events on an existing snowpack, which is often the case at $\mathrm{SH} 22$ where $>40 \%$ of all 336 calculated snowfall events (sum of consecutive hours with ongoing snowfall) result in snow cover only $1-2 \mathrm{~cm}$ thick. As frequent, light, snowfall events are typical for glaciers in the outer tropics, especially in the dry season, we surmise that a similar problem is likely to affect surface albedo calculated for Glaciar Zongo (Sicart and others, 2011) using the parameterization of the US Army Corps of Engineers (1956). As albedo schemes are in many cases the largest source of errors (Klok, 2004), modifying the range of albedo input parameters or modifying the parameterization used in the MB model might lead to improved performance. For example, Brock and others (2000) developed a parameterization scheme for surface albedo of a midlatitude glacier as a function of cumulative daily maximum temperatures greater than $0^{\circ} \mathrm{C}$ which performed better than previously published parameterizations. Another potentially helpful modification of the applied albedo scheme (Oerlemans and Knap, 1998) could be to account for the snow albedo before the event (Machguth and others, 2008) or to keep track of the surface albedo prior to a snowfall event, and reset it to this value if the fresh snow layer vanishes before it has completed the model-defined ageing time. More complex albedo schemes are not easily applicable at Glaciar
Shallap because they require extensive high-quality measurements for calibration, and further alternatives require accurate information on snow grain size (e.g. Wiscombe and Warren, 1980; Gardner and Sharp, 2010), that are not available at this site.

\section{CONCLUSION AND OUTLOOK}

Relative surface height change for hydrological years 2006/ 07 and 2007/08, calculated for two points on Glaciar Shallap using a process-based mass-balance model, yields a good match to measured surface height change $(<10 \%$ RMSD between measurements and model) when the model is implemented with locally optimized parameter combinations. However, the evaluation of the optimized model for two separate years and two separate stake locations reveals different determinations of model skill, which must be accounted for when distributing the model across the whole glacier surface, or applying the model outside the optimization period. We found at our study site that even the transfer of a parameter combination optimized for a single point in space and time to another location within the ablation zone of the same glacier, with a separation of $<800$ horizontal and $<60$ vertical meters, can lead to large additional errors in modeled cumulative mass balance compared to the optimized parameter combination, of up to $3179 \mathrm{~mm}$ ice eq. $\mathrm{a}^{-1}$.

Model errors increase noticeably during periods with frequent snowfall and snow cover. An apparent weakness of the albedo scheme used within our MB model when applied to Glaciar Shallap is the treatment of small snowfall events. Our findings suggest that albedo parameterizations for cases where frequent light snowfall events occur over existing snowpacks with low snow albedo should consider the albedo value of the old snow and be reset to this underlying snow albedo once the shallow fresh snow layer has ablated (Machguth and others, 2008). Alternatively, different albedo schemes (e.g. Brock and others, 2000; Gardner and Sharp, 2010) could be tested for this field site and implemented within the $M B$ model where adequate input data are available.

In both hydrological years our study site was located slightly below the equilibrium line (to be expected from 
measurements in Fig. 3), which at low latitudes means that the position of the transient snowline fluctuates frequently within this stake area throughout the year, so the spatial and temporal variability of surface albedo and melt is very high (e.g. Brock and others, 2000; Favier and others, 2004a). Given the sensitivity of the model transferability to the surface snow condition, this is likely to result in especially high errors within our study site, and the errors associated with spatial and temporal transfer of parameterizations presented here are likely to be an upper limit. It also seems that in order to obtain accurate results of high temporal resolution runoff production from Glaciar Shallap it will be necessary to ensure that the model system used can accurately reproduce the transient snowline, which is a challenging problem in tropical environments where accumulation and ablation occur year round.

The absolute magnitude of the errors associated with spatial and temporal transfer of parameterizations as presented here is larger than in MacDougall and Flowers (2011). Yet, as the year-round melt on ablation zones of tropical glaciers is much higher than seasonal melt in the sub-Arctic, the relative errors are comparable to the RMSD of up to $30 \%$ between modeled and measured mass balance in MacDougall and Flowers (2011).

Overall, this study presents a case for more rigorous assessment of small-scale spatial and temporal transferability of parameterized models due to further work to understand reasons for the variability in model skill in different climatic regions. This will improve the robustness of process-based mass-balance models that are needed for calculating glacier contribution to runoff at high temporal resolution and to understand the atmospheric controls on glacier meltwater production for climate-change impact assessments on catchment water resources in the Peruvian Andes (Bury and others, 2011).

\section{ACKNOWLEDGEMENTS}

This work is funded by the Austrian Science Fund (FWF project I 900-N21) and was supported by the Vizerektorat für Forschung, University of Innsbruck (PhD grant Wolfgang Gurgiser). We thank Regine Hock and an anonymous reviewer for substantially improving the manuscript. We also thank Ben Marzeion for advice on cross-validation; Jesus Gomez and the Unidad de Glaciología y Recursos Hídricos for sharing information and measurement data; Irmgard Juen, Marlis Hofer, Stephan Galos and Martin Großhauser for sharing AWS data; and Hector Oropeza and his team for excellent assistance during the fieldwork.

\section{REFERENCES}

Bintanja R and Van den Broeke MR (1995) The surface energy balance of Antarctic snow and blue ice. J. Appl. Meteorol., 34(4), 902-926 (doi: 10.1175/1520-0450(1995)034<0902:TSEBOA> 2.0.CO;2)

Braithwaite RJ (1995) Positive degree-day factors for ablation on the Greenland ice sheet studied by energy-balance modelling. J. Glaciol., 41(137), 153-160

Brock BW, Willis IC and Sharp MJ (2000) Measurement and parameterization of albedo variations at Haut Glacier d'Arolla, Switzerland. J. Glaciol., 46(155), 675-688 (doi: 10.3189/ 172756500781832675)

Brock BW, Willis IC and Sharp MJ (2006) Measurement and parameterization of aerodynamic roughness length variations at
Haut Glacier d'Arolla, Switzerland. J. Glaciol., 52(177), 281-297 (doi: 10.3189/172756506781828746)

Bury JT and 7 others (2011) Glacier recession and human vulnerability in the Yanamarey watershed of the Cordillera Blanca, Peru. Climatic Change, 105(1-2), 179-206 (doi: 10.1007/ s10584-010-9870-1)

Carenzo M, Pellicciotti F, Rimkus S and Burlando P (2009) Assessing the transferability and robustness of an enhanced temperature-index glacier-melt model. J. Glaciol., 55(190), 258-274 (doi: 10.3189/002214309788608804)

Condom T and 9 others (2011) Modelling the hydrologic role of glaciers within a Water Evaluation and Planning System (WEAP): a case study in the Río Santa watershed (Peru). Hydrol. Earth Syst. Sci., 8(1), 869-916 (doi: 10.5194/hessd-8-869-2011)

Cullen NJ, Mölg T, Kaser G, Steffen K and Hardy DR (2007) Energy balance model validation on the top of Kilimanjaro, Tanzania, using eddy covariance data. Ann. Glaciol., 46, 227-233 (doi: 10.3189/172756407782871224)

Etchevers P and 22 others (2004) Validation of the energy budget of an alpine snowpack simulated by several snow models (SnowMIP project). Ann. Glaciol., 38, 150-158 (doi: 10.3189/ 172756404781814825)

Favier V, Wagnon P, Chazarin JP, Maisincho L and Coudrain A (2004a) One-year measurements of surface heat budget on the ablation zone of Antizana Glacier 15, Ecuadorian Andes. J. Geophys. Res., 109(D18), D18105 (doi: 10.1029/ 2003JD004359)

Favier V, Wagnon Pand Ribstein P (2004b) Glaciers of the outer and inner tropics: a different behaviour but common response to climatic forcing. Geophys. Res. Lett., 31(16), L16403 (doi: 10.1029/2004GL020654)

Francou B, Vuille M, Favier V and Cáceres B (2004) New evidence for an ENSO impact on low-latitude glaciers: Antizana 15, Andes of Ecuador, 0²8'S. J. Geophys. Res., 109(D18), D18106 (doi: 10.1029/2003JD004484)

Gardner AS and Sharp MJ (2010) A review of snow and ice albedo and the development of a new physically based broadband albedo parameterization. J. Geophys. Res., 115(F1), F01009 (doi: 10.1029/2009JF001444)

Georges C (2004) 20th century glacier fluctuations in the tropical Cordillera Blanca, Peru. Arct. Antarct. Alp. Res., 36(1), 100-107 (doi: 10.1657/1523-0430(2004)036[0100: TGFITT]2.0.CO;2)

Gromke C, Manes C, Walter B, Lehning M and Guala M (2011) Aerodynamic roughness length of fresh snow. Bound.-Layer Meteorol., 141(1), 21-34 (doi: 10.1007/s10546-011-9623-3)

Hock R (2005) Glacier melt: a review on processes and their modelling. Progr. Phys. Geogr., 29(3), 362-391 (doi: 10.1191/ 0309133305pp453ra)

Hock R and Holmgren B (2005) A distributed surface energybalance model for complex topography and its application to Storglaciären, Sweden. J. Glaciol., 51(172), 25-36 (doi: 10.3189/172756505781829566)

Hofer M, Mölg T, Marzeion B and Kaser G (2010) Empiricalstatistical downscaling of reanalysis data to high-resolution air temperature and specific humidity above a glacier surface (Cordillera Blanca, Peru). J. Geophys. Res., 115(D12), D12120 (doi: 10.1029/2009JD01255)

Juen I, Kaser G and Georges C (2007) Modelling observed and future runoff from a glacierized tropical catchment (Cordillera Blanca, Perú). Global Planet. Change, 59(1-4), 37-48 (doi: 10.1016/j.gloplacha.2006.11.038)

Kaser G (2001) Glacier-climate interaction at low latitudes. J. Glaciol., 47(157), 195-204 (doi: 10.3189/ 172756501781832296)

Kaser G, Juen I, Georges C, Gomez J and Tamayo W (2003) The impact of glaciers on the runoff and the reconstruction of mass balance history from hydrological data in the tropical Cordillera Blanca, Peru. J. Hydrol., 282(1-4), 130-144 (doi: 10.1016/ S0022-1694(03)00259-2) 
Klok EJ (2004) Modelled climate sensitivity of the mass balance of Morteratschgletscher and its dependence on albedo parameterization. Int. J. Climatol., 24(2), 231-245 (doi: 10.1002/joc.994)

Klok EJ and Oerlemans J (2002) Model study of the spatial distribution of the energy and mass balance of Morteratschgletscher, Switzerland. J. Glaciol., 48(163), 505-518 (doi: 10.3189/172756502781831133)

MacDougall AH and Flowers GE (2011) Spatial and temporal transferability of a distributed energy-balance glacier melt model. J. Climate, 24(202), 1480-1498 (doi: 10.1175/2010JCLI3821.1)

Machguth H, Purves RS, Oerlemans J, Hoelzle M and Paul F (2008) Exploring uncertainty in glacier mass balance modelling with Monte Carlo simulation. Cryosphere, 2(2), 191-204 (doi: 10.5194/tc-2-191-2008)

Mark BG, Bury J, McKenzie JM, French A and Baraer M (2010) Climate change and tropical Andean glacier recession: evaluating hydrologic changes and livelihood vulnerability in the Cordillera Blanca, Peru. Ann. Assoc. Am. Geogr., 100(4), 794-805 (doi: 10.1080/00045608.2010.497369)

Mölg Tand Hardy DR (2004) Ablation and associated energy balance of a horizontal glacier surface on Kilimanjaro. J. Geophys. Res., 109(D16), D16104 (doi: 10.1029/2003JD004338)

Mölg T, Cullen NJ, Hardy DR, Kaser G and Klok L (2008) Mass balance of a slope glacier on Kilimanjaro and its sensitivity to climate. Int. J. Climatol., 28(7), 881-892 (doi: 10.1002/joc.1589)

Mölg T, Cullen NJ and Kaser G (2009a) Solar radiation, cloudiness and longwave radiation over low-latitude glaciers: implications for mass-balance modelling. J. Glaciol., 55(190), 292-302 (doi: 10.3189/002214309788608822)

Mölg T, Cullen NJ, Hardy DR, Winkler M and Kaser G (2009b) Quantifying climate change in the tropical midtroposphere over East Africa from glacier shrinkage on Kilimanjaro. J. Climate, 22(15), 4162-4181 (doi: 10.1175/2009JCLI2954.1)

Mölg T, Maussion F, Yang W and Scherer D (2012) The footprint of Asian monsoon dynamics in the mass and energy balance of a Tibetan glacier. Cryos. Discuss., 6(4), 3243-3286 (doi: 10.5194/ tcd-6-3243-2012)

Nicholson L, Prinz R, Mölg T and Kaser G (2012) Micrometeorological conditions and surface mass and energy fluxes on Lewis glacier, Mt Kenya, in relation to other tropical glaciers. Cryos. Discuss., 6(6), 5181-5224 (doi: 10.5194/tcd-6-5181-2012)

Oerlemans J and Knap WH (1998) A 1-year record of global radiation and albedo in the ablation zone of Morteratschgletscher, Switzerland. J. Glaciol., 44(147), 231-238

Rabatel A and 27 others (2012) Review article of the current state of glaciers in the tropical Andes: a multi-century perspective on glacier evolution and climate change. Cryos. Discuss., 6(4), 2477-2536 (doi: 10.5194/tcd-6-2477-2012)

Reijmer CH and Hock R (2008) Internal accumulation on Storglaciären, Sweden, in a multi-layer snow model coupled to a distributed energy- and mass-balance model. J. Glaciol., 54(184), 61-72 (doi: 10.3189/002214308784409161)

Sicart JE, Ribstein P, Wagnon P and Brunstein D (2001) Clear-sky albedo measurements on a sloping glacier surface: a case study in the Bolivian Andes. J. Geophys. Res., 106(D23), 31729-31738 (doi: 10.1029/2000JD000153)

Sicart JE, Wagnon P and Ribstein P (2005) Atmospheric controls of the heat balance of Zongo Glacier ( $16^{\circ} \mathrm{S}$, Bolivia). J. Geophys. Res., 110(D12), D12106 (doi: 10.1029/2004JD005732)

Sicart JE, Ribstein P, Francou B, Pouyaud B and Condom T (2007) Glacier mass balance of tropical Zongo glacier, Bolivia, comparing hydrological and glaciological methods. Global Planet. Change, 59(1-4), 27-36 (doi: 10.1016/j.gloplacha.2006.11.024)

Sicart JE, Hock R, Ribstein P and Chazarin JP (2010) Sky longwave radiation on tropical Andean glaciers: parameterization and sensitivity to atmospheric variables. J. Glaciol., 56(199), 854-860 (doi: 10.3189/002214310794457182)

Sicart JE, Hock R, Ribstein P, Litt M and Ramirez E (2011) Analysis of seasonal variations in mass balance and meltwater discharge of the tropical Zongo Glacier by application of a distributed energy balance model. J. Geophys. Res., 116(D13), D13105 (doi: 10.1029/2010JD015105)

US Army Corps of Engineers (1956) Snow hydrology: summary report of the snow investigations. North Pacific Division, US Army Corps of Engineers, Portland, OR

Van As D, Van den Broeke MR, Reijmer C and Van de Wal R (2005) The summer surface energy balance of the high Antarctic plateau. Bound.-Layer Meteorol., 115(2), 289-317 (doi: 10.1007/s10546-004-4631-1)

Viviroli D and 15 others (2011) Climate change and mountain water resources: overview and recommendations for research, management and policy. Hydrol. Earth Syst. Sci., 15(2), 471-504 (doi: 10.5194/hess-15-471-2011)

Vuille $M$ and 6 others (2008) Climate change and tropical Andean glaciers: past, present and future. Earth-SCi. Rev., 89(3-4), 79-96 (doi: 10.1016/j.earscirev.2008.04.002)

Wagnon P, Ribstein P, Kaser G and Berton P (1999) Energy balance and runoff seasonality of a Bolivian glacier. Global Planet. Change, 22(1-4), 49-58

Wagnon $\mathrm{P}$, Lafaysse $\mathrm{M}$, Lejeune $\mathrm{Y}$, Maisincho $\mathrm{L}$, Rojas $\mathrm{M}$ and Chazarin JP (2009) Understanding and modeling the physical processes that govern the melting of snow cover in a tropical mountain environment in Ecuador. J. Geophys. Res., 114(D19), D19113 (doi: 10.1029/2009JD012292)

Wilks DS (2011) Statistical methods in the atmospheric sciences, 3rd edn. (International Geophysics Series 100) Academic Press, Oxford

Wiscombe WJ and Warren SG (1980) A model for the spectral albedo of snow. I. Pure snow. J. Atmos. Sci., 37(12), 2712-2733 (doi: 10.1175/1520-0469(1980)037<2712:AMFTSA>2.0.CO;2)

\section{APPENDIX}

Table 6. Input parameters for the MB model with base value $(\mathrm{V})$ and range $(\mathrm{R})$ were either taken from or derived from the stated literature sources following the study of Mölg and others (2012) or are estimates from field measurements at our site. Parameters to which the mass balance shows the most sensitive response as identified by the test procedure (Section 2.3; Fig. 5) are indicated in bold

\begin{tabular}{|c|c|c|c|}
\hline & Parameter(ization) & Value and range & Source \\
\hline P1 & Vertical air temperature gradient & $\begin{array}{c}\mathrm{V}:-0.55^{\circ} \mathrm{C}(100 \mathrm{~m})^{-1} \\
\mathrm{R}: \pm 10 \%\end{array}$ & Sicart and others (2011); assumed \\
\hline P2 & Vertical precipitation gradient & $\begin{array}{c}\mathrm{V}:+5 \%(100 \mathrm{~m})^{-1} \\
\mathrm{R}: \pm 5 \%\end{array}$ & Condom and others (2011); assumed \\
\hline P3 & Upper threshold for precipitation phase (all liquid above) & $\begin{array}{c}\mathrm{V}: 2.5^{\circ} \mathrm{C} \\
\mathrm{R}: \pm 0.5^{\circ} \mathrm{C}\end{array}$ & assumed \\
\hline $\mathbf{P 4}$ & Lower threshold for precipitation phase (all solid below) & $\begin{array}{c}\mathrm{V}: 1.0^{\circ} \mathrm{C} \\
\mathrm{R}: \pm 0.5^{\circ} \mathrm{C}\end{array}$ & assumed \\
\hline
\end{tabular}


Table 6. (continued)

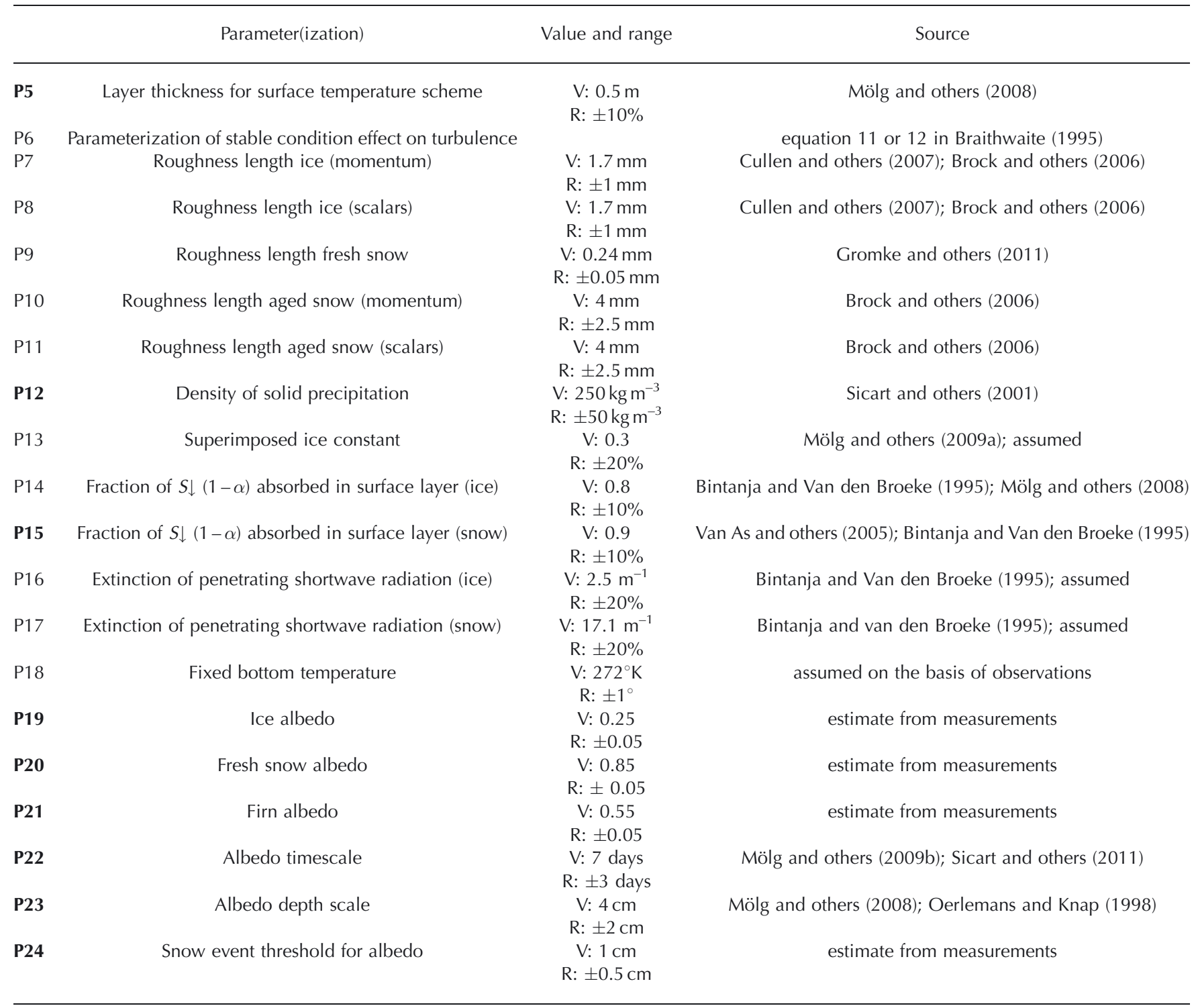

MS received 3 December 2012 and accepted in revised form 28 April 2013 